\title{
INNOVATION DYNAMICS, BEST PRACTICES, AND TRENDS IN THE OFF-GRID CLEAN ENERGY MARKET
}

\author{
JAMES L. KOCH \\ Santa Clara University \\ Santa Clara, California, U.S.A. \\ jkoch@scu.edu
}

\author{
A.L. HAMMOND \\ Ashoka \\ Arlington, Virginia, U.S.A. \\ al.hammond@gmail.com
}

Abstract. In 2008, the authors of this article developed a "sector strategy" for the Global Social Benefit Incubator (GSBI) at Santa Clara University with the purpose of facilitating collaborative learning between BoP ventures, technology and business model innovation, and positive ecologies for cluster development. This article summarizes insights from the GSBl's involvement with 60 ventures in the BoP clean energy sector.

Acknowledgements. The authors gratefully acknowledge support from the Center for Science, Technology, and Society at Santa Clara University, the generous support of the Skoll Foundation for the Global Social Benefit Incubator, and Applied Materials for support of the GSBI Energy Sector Strategy. They also wish to express their thanks to Thane Kreiner, Eric Carlson, Andrew Lieberman, Nancy Wimmer, and Jean Hazell for their valuable comments on an earlier version of this article. 
Base of the Pyramid (BoP) markets for off-grid clean energy-the 2+ billion people in low-income communities with unreliable access to electric power or none at all, who pay high prices for imported fuels, or who rely on biomass for cooking over open fires-represent a huge and growing opportunity. Now-outdated estimates based on national household surveys suggest that this market was worth at least $\$ 433$ billion seven years ago (Hammond, Kramer, Tran, Katz, \& Walker, 2007). With the addition of substantial demand for recharging mobile devices, efficient LED lights, the discovery of a host of specific energy load market segments by social entrepreneurs, and rising incomes in developing countries, we believe that this market now exceeds $\$ 1$ trillion. The disconnect between the size of this market and current penetration rates of less than two percent (Bardouille, 2012) suggests a significant opportunity for social entrepreneurs and impact investors who seek to help in bringing off-grid BoP clean energy markets into the economic mainstream.

Several factors contribute to this opportunity. Globally, growing concerns about climate change have stimulated huge public and private sector investments in renewable energy technologies. In the solar market, for example, recent declines in the price of solar cell components have brought solar systems within the buying power of low-income consumers. The steady advance of technology has improved the performance and reliability of solar products, is yielding combined solar/IT system solutions for serving markets via mobile telecom networks, and is leading to a wide variety of niche products. At the same time, growing BoP consumer demand and ability to pay is expanding the potential market-if last-mile distribution and other bottlenecks can be resolved.

This article identifies trends and best practices in overcoming barriers to growth in the off-grid clean energy market. It is based on an analysis of over 60 social enterprises in this sector and the tacit knowledge of the entrepreneurs behind these ventures. All of the BoP clean energy enterprises recognized by the Tech Awards ${ }^{1}$ between 2001 and 2012 are represented, as well as all of the BoP clean energy enterprises selected for participation in the Global Social Benefit Incubator (GSBI) at Santa Clara University between 2003 and 2012. Access to profiles for each of these organizations is available through the Energy Map (www.energymap-scu.org).

${ }^{1}$ An international program co-sponsored by the Tech Museum of Innovation, Applied Materials, and the Center for Science, Technology, and Society at Santa Clara University. See box on p. 123. 
Over the twelve-year history of the Tech Awards, a large percentage of the Tech Laureates in the energy sector have focused on BoP markets where the lack of access to energy and other vital services are barriers to escaping from extreme poverty. In addition to proof of concept and evidence of a superior solution relative to alternatives, the potential for replication and scaling are pivotal criteria in the final selection of Tech Laureates.

GSBI social enterprises are selected based on their potential to scale social impact. The most common social outcome metric across these ventures is the number of people with access to clean energy. The GSBI integrates distance-based education and an in-residence boot camp with intensive mentoring by seasoned Silicon Valley entrepreneurs and venture capitalists. Over $50 \%$ of the 160 enterprises that have graduated from this program have become economically viable with positive operating cash flows and significant increases in social impact.

\section{CHARACTERISING THE DATA SET AND ITS SOCIAL AND EVINRONMENTAL SIGNIFICANCE}

While several multi-national companies are engaged in serving offgrid energy markets, multi-national corporation (MNC) involvement is primarily a CSR activity. All of the 60 organizations in our data set are social mission enterprises-their purpose for being is to address the need to increase access to affordable clean energy for the poor. Most seek to be economically self-sustaining and nearly half are for-profit businesses $-45 \%$ are structured as for-profit organizations, $28 \%$ are hybrids, and only $27 \%$ are non-profits. The for-profit enterprises seek to leverage mission aligned investment capital and are pursuing the long-term goal of achieving organic growth through earned income, while hybrid ventures rely on a combination of contributed or grant resources and earned income. To achieve their social mission, the founders of these enterprises must simultaneously innovate along three dimensions-technology localization, business models, and adaptation to ecosystems characterized by extreme infrastructure and distribution constraints. Limited access to financial and human capital as well as other resources has made frugal innovation a necessity for all of these ventures. These constraints are especially onerous in rural markets, which are the primary focus for more than $80 \%$ of our sample organizations.

Although extremely fragmented, the BoP energy market holds tremendous potential as an engine for increasing human productivity, material standards of living, and quality of life. The use of kerosene lanterns for 
room and task lighting and the even more widespread use of biomass fuels for cooking are an energy poverty trap at the base of the pyramid. The poor pay more for these inferior and harmful energy sources than wealthier customers who have access to modern light and power. Inefficient stoves and kerosene also contribute to severe respiratory and other health impacts, as well as high carbon emissions and environmental degradation. In addition, the lack of access to power and light limits household earnings and reduces the opportunity for children to study and learn in the evenings, thereby contributing to an intergenerational poverty trap.

\section{Deployable Technologies}

Twelve technology categories are represented in this sample. Each is modular and can be sized to meet specific energy load requirements and the economics of buyer demand in widely distributed, low density environments. In the BoP, demand-based solutions generally involve the micro-provisioning of energy. For example, the average solar home system is about 50 watts, community scale gasification plants typically provide up to 7 hours of energy per day, and task solutions are targeted at narrowly defined load requirements such as milk chilling, sewing, water pumping, or as back-up energy with specific economic value propositions in regions with unreliable grid power.

The frequency of various technologies in use across our sample of 60 enterprises is summarized in Table 1 . Both biomass and solar technologies are widely deployed solutions. Our work with enterprises in these areas has identified a number of recurring patterns in mechanisms for overcoming local barriers. For small hydro, wind, and fuel cell ventures in the Energy Map, our review suggests that, although the evidence is more limited due to small sample sizes, these are also economically viable technologies with significant potential for social impact in specific regional contexts.

\section{Geography and Mental Maps of "Scale"}

Several of the geographically focused enterprises in our sample have experimented in developing solutions that span more than one technology. This has enabled them to leverage local market knowledge and adapt product offerings to serve multiple market segments. In some instances, these product extensions build on competencies in a particular core technology. Fixed panel solar ventures, for example, may develop solar lantern technology offerings to serve those who cannot afford their entry solar home systems and subsequently expand into commercial or even community scale solutions. In contrast, community-based NGOs 
are more likely to be involved in developing offerings that span both efficient biomass cooking stoves and solar lanterns. Their ability to extend offerings across multiple technologies can contribute to greater market penetration and depth of impact within a particular region or territory (Desa \& Koch, 2013). This is a desirable attribute for acquiring donors or investors with a particular geographic focus. By spreading the costs of developing distribution channels across multiple products, it can also contribute to capital efficiency. At the same time, however, being spread thinly across multiple changing technologies can undermine the ability to develop the formal knowledge, efficient systems, and competencies needed for replication across wider geographic territories.

\begin{tabular}{|c|c|c|}
\hline Technology & $\begin{array}{c}\text { No. of } \\
\text { Organizations* }\end{array}$ & Example \\
\hline Biodiesel & $\mathbf{7}$ & Mali Biocarburant (Mali) \\
\hline $\begin{array}{c}\text { Biomass } \\
\text { Gasification }\end{array}$ & 4 & Husk Power Systems (India) \\
\hline $\begin{array}{c}\text { Efficient } \\
\text { Burning Stoves }\end{array}$ & 11 & Potential Energy (Ethiopia) \\
\hline Biomass Briquettes & 3 & Nishant (India) \\
\hline Biogas Digesters & 4 & Cows to Kilowatts (Nigeria) \\
\hline $\begin{array}{c}\text { Biomass Power } \\
\text { (Total) }\end{array}$ & $\mathbf{3 0}$ & Tough Stuff (Africa) \\
\hline Fixed Panel Solar & 22 & Grameen Shakti (Bangladesh) \\
\hline Portable Solar & 18 & Practical Action (Peru) \\
\hline Solar (Total) & $\mathbf{4 0}$ & Blue Energy (Nicaragua) \\
\hline Small Hydro & 1 & IDE (India) \\
\hline Wind & 1 & AEDC (South Africa) \\
\hline Human Power & 4 & E. Wind Laboratories (Nigeria) \\
\hline Fuel Cells & 1 & $\mathbf{7}$ \\
\hline Other (Total) & 4 & \\
\hline $\begin{array}{c}\text { Efficient Grid } \\
\text { Energy Use }\end{array}$ & & \\
\hline
\end{tabular}

Table 1. Sources of Power: Deployable Technologies

*Total (81) exceeds sample sized due to enterprises with scope that spans more than a single technology. 


\section{ATTRACTIVE SEGMENTS}

While the BoP clean energy sector lacks the cohesiveness of more established industrial markets, it can be categorized into four primary segments. In our research, we consider empirical regularity in the pattern of findings within a given segment as evidence of learning and adaptation. As mentors to ventures in this sector, these findings and the direction of sector-wide change over time inform our insights about the antecedents of firm survival and the emergence of best practices. Identifying robust patterns of success in localizing technology, business model innovation, and adaptation to resource constrained environments is critically important in mitigating the risks associated with the introduction of new products in new markets.

Using the frequency or population of ventures in a given segment as a proxy for learning, the off-grid light and power segments reflect areas in which the greatest learning is likely to be occurring through the normal process of variation, adaptation, and selection. Our findings and work with BoP social entrepreneurs within the energy cluster suggest that greater levels of entrepreneurial ferment are leading to increases in the functional value of technology solutions and the perceived value or acceptance of these solutions. The activation of these markets facilitates the benchmarking of products, business models, and market creation strategies. For investors, awareness of such benchmarking may reduce technological risk and the liability of newness in previously underserved markets. The findings in Table 2 suggest that off-grid community scale power, home and business energy applications, and portable device market segments are poised for "take off" or acceleration.

\begin{tabular}{|c|c|}
\hline (1) Off-Grid Light and Power & Total 54 \\
\hline - Centralized, community-scale light and power & 9 \\
\hline - Individual home and business light and power & 20 \\
\hline - Portable power products & 25 \\
\hline (2) Clean Cooking & Total 20 \\
\hline - More efficient stoves & 11 \\
\hline - Clean fuel sources & 9 \\
\hline $\begin{array}{c}\text { (3) Motive Power- } \\
\text { powering engines and generators }\end{array}$ \\
\hline (4) Powering specialized products and services & $\mathbf{7 1}$ \\
\hline
\end{tabular}

Table 2. Market Segments (by Use) 
In Table 3 below, several of the more general segments in Table 2 are further refined to identify targets of investable opportunity, with large markets and identifiable economic buyers as units of analysis for assessing the viability of business models (e.g., region, community, household, commercial scale). In several of these target areas, favorable macro trends exist (e.g., cheaper equipment, value chain specialization, standards, enabling public policy, increasingly favorable price-performance comparisons with alternative or extant solutions). In these contexts, value propositions and unit economics or incentives to buy can be compelling. In addition, the success factor checklists from proven business models can serve as guides for stress testing the expense and revenue assumptions in enterprise growth plans.

\begin{tabular}{|c|c|}
\hline Technologies & Positive Unit Economics \\
\hline Biomass & - National region \\
\hline - Biofuel & - Community scale \\
\hline - Biomass Gasification & $\begin{array}{c}\text { - Commercial scale } \\
\text {-Household scale }\end{array}$ \\
\hline - Bio-digesters & $\begin{array}{c}\text { - Household scale } \\
\text {-Efficient stoves }\end{array}$ \\
\hline Solar Power & - Commercial scale (limited evidence) \\
\hline - Fixed Panel & - Household and commercial scale \\
\hline - Portable & - Household and individual use cases \\
\hline Other & \\
\hline - Small Hydro & - Community scale \\
\hline - Fuel cells & - Household scale \\
\hline - LPG & - Household and commercial scale \\
\hline
\end{tabular}

Table 3. Technology Subsectors and Unit Economics

Column two of Table 3 identifies investment target areas and the appropriate units of analysis or aggregation for assessing the scalability of business models. There is significant potential for social impact returns in these target areas. In the section that follows, we identify areas in which the experience and tacit knowledge of social entrepreneurs can ground investor understandings of the financial, time, and other resources that may be needed to realize this potential. This insight from 
the field is needed to avoid disconnects between investor expectations and the complexity of BoP market realities (Kohler, Kreiner, \& Sawhney, 2011; Koh, Karmchandani, \& Katz, 2012).

\section{SUCCESS FACTORS}

From the authors' work with dozens of the BoP clean energy ventures in this study, it is evident that a growing body of field-based knowledge exists in this sector. While yet to be formalized, it is driving bottom-up innovation through on-the-ground networks of practice that are little understood by outsiders. The GSBI Energy Sector initiative at Santa Clara University is a bridge to these networks. It taps into this practice-based knowledge and integrates these insights into formal programs of instruction and mentoring, as well as broader efforts that address the need to build institutional and financial systems to facilitate growth. Illustrations of this field-based knowledge can be seen in Figure 1 below-one of many graphic recordings from a 2011 GSBI clean energy sector workshop with eleven (18\%) of the ventures in our sample of 60 social businesses.

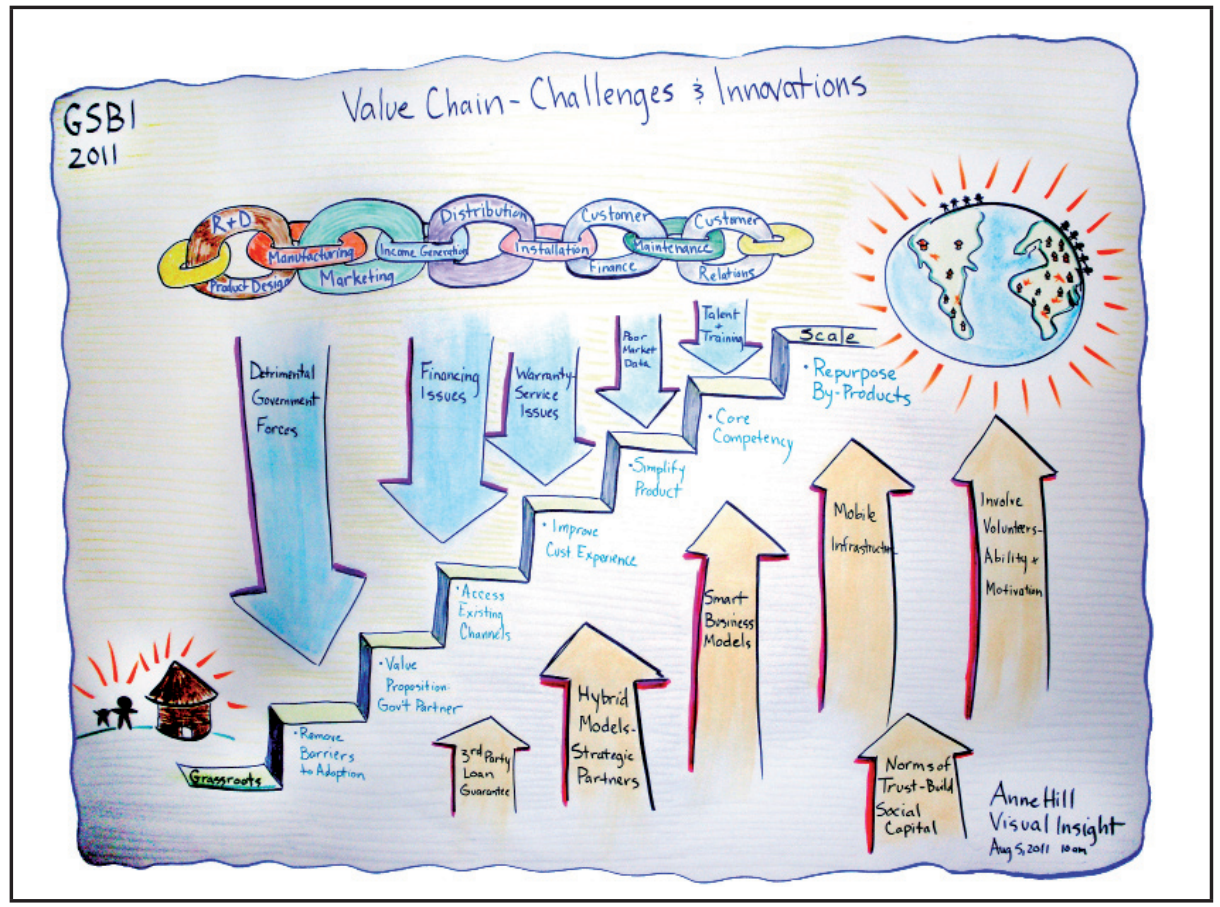

Figure 1. Field-Based Knowledge: Value Chain Innovations to Enhance Scaling Potential 
Innovation Dynamics, Best Practices, and Trends in the Off-Grid Clean Energy Market 129

Across the spectrum of clean energy solutions in our study we have identified three factors that are key to the success of start-ups: market creation, the integrative capacity of leadership teams, and feedback loops for enhancing organizational learning and social impact.

\section{Market Creation}

To be successful in addressing needs in off-grid markets, start-ups must increase the functional value of technology solutions as well as the perceived value and acceptance of product or service designs. Our work with energy cluster ventures has identified three "stress test" dimensions for assessing the viability of market creation investments.

Social Marketing. Customer education is a pivotal factor in market creation and often underestimated as a critical expense in business models.

Brand Building. Trust is a critical factor in market entry and the ability to become a trusted brand is essential to market penetration and overcoming the "market spoilage" from cheap solutions that have failed in the past. Investing in product aesthetics, durability, and after market service is important in brand building.

Customer and Supplier Finance. Even with extreme affordability as a design criterion for entry products, customer finance trumps price in BoP contexts where the "upfront" cost of ownership is a more important factor in purchase decisions than incrementally lower prices. Similarly, the working capital needs of SME suppliers and micro-franchisees must be addressed where they factor in the unit economics of value chain stakeholders.

\section{Integrative Capacity}

Given the need to build and integrate complex value chains, investments in overcoming human capital constraints and organizational development are significantly overlooked factors in many business models. Overlooking these factors contributes to hubris, especially regarding execution capacity and distribution.

Organizational scaling mechanisms-skills, structure, processes, and systems-are generally underdeveloped and a major risk factor in BoP start-ups. As Larry Bossidy and Ram Charan (2002) posit in their best selling book, Execution-The Discipline of Getting Things Done, people and operations are key to execution. In our work with many of the ven- 
tures in this sample, expense and growth capital forecasts frequently underestimate the importance of human capital and the need for technical services support, strengthening operating systems, and deepening organizational leadership.

Distribution. Last mile distribution is the single most difficult challenge to overcome in serving fragmented BoP off-grid energy markets, nearly $80 \%$ of which we estimate are in rural areas. Incentives and unit economics, or an understanding of how each link in the value chain makes money, are key success factors in agent-based distribution systems. The development of robust and stable rural distribution systems remains a fundamental obstacle that merits additional attention in efforts to catalyze diffusion and strengthen market penetration.

\section{Enhancing Learning and Social Impact}

Scale is best achieved by "demand-based" solutions with clear evidence of an economic surplus for the poor. This surplus can be measured in both energy savings and increases in productivity, household earnings, or quality of life due to energy access. In the absence of the ability to capture benefits locally, environmental externalities are less likely to be a driver in purchase decisions for those at the edge of extreme poverty.

\section{FIELD-BASED KNOWLEDGE AND VALUE CHAIN INNOVATION}

The graphic recording in Figure 1 depicts the collective intelligence of the 2011 clean energy workshop participants as a force field with barriers as "down" arrows. For investors, these can be thought of as risk factors. Enablers are depicted as "up" arrows. Evidence of their existence and incorporation into business models should be viewed as positives by investors. A linked chain appears across the top of this graphic as a metaphor for the key elements in BoP value chains. A practitioner guide to "best practices" for taking grassroots learning to scale is depicted as ascending steps.

Participants in this GSBI workshop and across our wider sample see the clean energy field as evolving in the direction of increased value chain specialization with fewer successful ventures likely to provide vertically integrated solutions. They see increased opportunities for "pure play" design, enabling mobile technology, manufacturing, distribution, and finance entities. Partnerships with the robust rural bank sector, for example, are seen as an effective alternative to self-financing. In a field that is populated by a growing number of new entrants and in need of becoming more rationalized, they envision increases in specialization 
and combinatory innovation occurring through value chain partners. Similarly, third party loan guarantees, hybrid business models that can leverage grants and volunteers for capacity building, mobile payment systems to facilitate micro-payment schemes, public-private partnerships, and alliances are all seen as potential mechanisms for creating novel and effective business models. Here, again, the collective intelligence of social entrepreneurs can aid investors who lack contextual perspectives about "what works" and "why" in BoP markets.

\section{Best Practices}

Business models involve tradeoffs. The choices that are made regarding the nature and scope of business activities and resource requirements are driven by a firm's value proposition and its mission. They can be translated into the expense and revenue drivers for creating customer value and ensuring the financial viability of an enterprise. In established industrial sectors and markets with several or many competitors, organizations deliberately choose a particular set of activities to deliver a unique mix of value to specific target customers. Differentiation, value, and low cost strategies are, essentially, the sum of these choices or decisions.

BoP markets are different. Ventures are often competing against nonconsumption, customers with limited and irregular cash flows are risk averse, and "low cost" provider is the only viable position. Paradoxically, brand building in these new markets is frequently contingent on the ability to provide and service products through paraskilled field coordinators and remote last mile distribution networks comprised of minimally educated agents. The need for total product solutions that combine ease of use and durability with low cost and greater convenience requires BoP ventures to pursue disruptive innovation strategies that can easily overstretch the resources and integrative capacity of their organizations.

We have identified several recurring business model themes and best practices from the 60 clean energy ventures examined in this study. These practices reflect strategic tradeoffs and the appropriate focusing of resources to create organizational competencies in each of the following areas:

- Product Design. Product design and localization are key success factors. For the 55 non-commodity ventures in our database, localizing technology in BoP markets involves choices regarding product or technology design and whether it should become an in-house competency or an outsourced activity ( $75 \%$ percent of these ventures 
see product design as an essential in-house activity). The ability to localize technology is a critical success factor for the majority of BoP energy ventures-for many, product design is a key differentiator.

- Standardization vs. Customization. Winning strategies balance standardization and customization tradeoffs. More than two-thirds (35) of the 51 product ventures in our sample offer standardized products. Customization was concentrated in two subsectors: a) community scale light and power and $\mathrm{b}$ ) solar home and business light and power. Low watt or energy output systems appear to seek brand differentiation through the user-centered design of standardized products for specific customer segments as opposed to customization for individual customers or households.

- Market Segmentation. Successful business models are based on effective market segmentation-the poor are not a homogeneous mass market. While solar lantern ventures offer standardized products, they increasingly offer a suite of such products to increase market penetration by addressing various BoP segments-from entry products such as \$20 lanterns for the BoP \$500-\$1000 annual per capita purchasing power parity market, to multiple LED solar kits for the BoP \$1000-\$1500 segment. In some instances, solar product suites extend all the way from lanterns to microgrids. Evidence of venture capacity to execute across this wider product spectrum, however, is limited.

- Manufacturing and Assembly. Local assembly facilitates the cultural embedding of solutions and value creation. Given the high percentage of firms with standardized products, the level of firm involvement in manufacturing and/or assembly was somewhat surprising. Fully $62 \%$ of the product ventures in our sample were involved in manufacturing or local assembly_primarily the latter. Both of these functions were outsourced by only $38 \%$. The rationale for involvement in assembly is closely linked to the need to develop the local knowledge needed to support after-market warranty and service capabilities. Local warranty support is important to becoming a trusted brand. Local assembly also creates livelihood opportunities and embeds technology solutions in local culture (Wimmer, 2012). In some instances, local assembly of standardized components may also reduce import tariffs. 
- Distribution. Last mile distribution is a make or break issue. Due to infrastructure deficits and inefficient markets, the area of greatest experimentation in serving BoP market segments is distribution. Most ventures develop and experiment with a variety of channels: 7\% report using existing retail channels, 33\% work through partners such as independent distributors, and 53\% have created their own direct sales channels for either retail (30\%) or contract and commercial sales (23\%); 28\% developed sales channels through local community organizations, cooperatives, or self-help groups; and, 25\% reached last mile markets through micro-franchise agents. Examples of country-level master distributor models, regional trading companies, and multi-tier franchising exist for less complex products like solar lanterns and stoves, but more complex product solutions like solar home systems and community scale biomass gasification require the replication of organizational capabilities through enterprise branching.

- Affordability and Customer Finance. Low-cost business models and access to credit are essential to the creation of inclusive markets, and frugal innovation acumen is essential in product design. Nearly half of Energy Map ventures (29 of 60) place a major emphasis on extreme affordability, and 43\% leverage donor funds for capacity development expenses to reduce the costs that are passed on in end-user pricing. To make above entry products affordable, customer finance through partner organizations (28\%) or in-house financing (22\%) is seen as critical to minimizing upfront costs for solar home systems, higherend lanterns, solar kits, and cooking stoves.

- Legal Structure and Firm Financing. Alternative legal structures are a key strategic factor in firm financing. A minority of Energy Map ventures (27\%) have chosen to operate as nonprofits, with an additional $28 \%$ operating as hybrids, and 45\% choosing to be for-profit entities. Friends, family, and volunteers were critical to early stage bootstrapping for $25 \%$ of these ventures, while grants and donations were a significant source of funding for $60 \%$ of the BoP clean ventures in the Energy Map database. In addition, loans and equity were used to fund development and growth in 50\% of this sample. A minority (17\%) has sought or plans to seek carbon credits as a source of firm financing, although all agree that certification is costly. 
- Scaling Strategies. Many ventures are not built to scale, and some are best suited to scale within a narrowly focused geography. Increasing the depth of market penetration by creating product suites with price points for lower and higher end segments in existing geographic markets and offering new products or services through existing channels are preferred scaling strategies for $27 \%$ of the Energy Map ventures. By comparison, $40 \%$ seek to expand to new geographic markets either through new distributors (17\%) or the creation of venture branches (23\%). While a variety of scaling strategies are evident, impact investors should note that only a minority of ventures seek geographic expansion. A clear tradeoff exists between deepening market penetration within a region and market expansion. For either strategy, investors should be alert to the need for a realistic appraisal of the unit economics of supply chains in projecting investment returns.

As mentors to dozens of BoP ventures, the authors believe that, in addition to facilitating firm survival, attention to the above factors will enhance the social and financial returns of investors. This onerous list of challenges suggests that leadership, human capital, and system considerations must become a more significant emphasis in efforts to design organizations for scale.

\section{Promising Trends}

Over the course of our decade of work with BoP energy ventures, social entrepreneurs have clearly demonstrated that demand-based markets exist. The willingness of customers to pay and the size of the market opportunity have driven the trend from NGO and nonprofit legal structures to hybrid and for-profit structures $(28 \%$ and $45 \%$ of the sample in this study, respectively). At the same time, while technology design innovation continues to be driven from below, it is increasingly able to tap global innovation capacity. The process of technology adaptation to BoP needs has leapfrogged from bricolage solutions based on locally available materials to solutions that tap sophisticated global expertise and markets for standard components with ever improving price-performance thresholds.

The five trends that we have identified in our field work and summarized below will serve as positive tail winds for accelerating innovation and growth in the off-grid energy market. 
1. A new wave of user-centered design will significantly accelerate market growth. Several examples of this trend exist. Selco and Grameen Shakti have kept product design and assembly close to the customer in order to develop a host of semi-custom solutions for refined market segments. In 2012, Shakti reached the one million mark in the number of solar home systems installed, and is installing nearly 1,000 systems per day (Wimmer, 2012). Similarly, d.light has now sold more than 12 million solar lanterns with standardized product suites for markets segmented by the ability to pay and other locally relevant criteria. Their products reflect the application of sophisticated user-design principles and best of breed components. Another example, this time of a clearly focused organizational competency in customizing solutions to fit local cooking practices in multiple regions, is Potential Energy, a cooking stove venture with core strengths in design and low cost IKEA-style packaging for local stove assembly. Andree Solser and Ashok Gadgil are among the many high tech product innovators who have zeroed in on BoP market needs. Like their counterparts at organizations such Angaza, Simpa Networks, and Promethean Power, they have a high potential to catalyze disruptive innovation.

2. Specialization in value chains is increasing technological innovation and is likely to increase future investment returns. In Africa, the off-grid energy market is growing at 90\% per year (Bardouille, 2012). In our work, we have identified examples of similarly high growth rates in solar lantern sales at d.light and solar home system sales at Grameen Shakti (Wimmer, 2012). With the BoP energy market approaching take-off velocity, new entrants can now assess a sector landscape that is characterized by increasing value chain specialization and opt to focus on a particular niche, as Solar Sister and Onergy are doing with their distribution business models. Similarly, Simpa Networks has developed software-enabled electronics to facilitate mobile micro-payment systems that can be licensed by others and could virtually eliminate upfront costs as a barrier to rapid market growth for solar lanterns and solar home systems. Its pay-as-you-go pricing innovation uses cell phone SMS messaging for transmitting "top up" prepayments. Combined solar/IT systems could thus make energy more widely accessible via telecom networks. It is axiomatic that specialization leads to increases in pro- 
ductivity and the rate of innovation. It also drives capital efficiency which, in turn, increases investor returns.

3. Market segmentation is sparking innovation in sizeable niche markets. In this article we have identified major segments, but large niche markets exist in health clinics, commercial sales, street lighting, back-up diesel, powering cell-phone towers, milk chilling, and numerous other areas. Around the world, cell-phone towers are being converted from diesel to renewable sources at a price of about $\$ 0.70 /$ kilowatt hour. In the milk chilling area, Promethean recently received an order for $50 \mathrm{milk}$ chillers from India's largest private dairy. In Nigeria, EastWind Laboratories has developed an innovative inverter battery solution as a replacement technology for the huge back-up diesel market, and Act-if Electropower is focused on developing customized solar street lighting solutions for poor communities in Mexico.

4. Industry standards, market research, and trade shows facilitated by the IFC-World Bank, United Nations, and others are addressing concerns about technology failure rates and deepening market intelligence. Many participants in our sample have cited market spoilage, largely attributed to the flooding of markets with cheap products from China, as a serious consumer impediment. Lighting Africa, a joint initiative of IFC and the World Bank, has now "certified" the quality of 49 off-grid lighting products. If the standards-setting practices in other sectors are any precedent, this nascent work will significantly influence market developments through the benchmarking of competitor products and by stimulating interoperability in supplier ecosystems. Trade shows like the Third International Off-Grid Lighting and Trade Fair in November 2012 will also facilitate industry-wide collaboration.

5. Significant global improvements are occurring in the price-performance of system components and appliances. The costs per watt for solar panels has declined by more than $70 \%$ in the last five years and the efficiency of LED's has improved at a rate analogous to Moore's law in semi-conductors. The lumen output of low cost solar lanterns is now up to 100 times brighter than kerosene lanterns, with payback periods measured in months. Similarly, innovation is accelerating in bat- 
Innovation Dynamics, Best Practices, and Trends in the Off-Grid Clean Energy Market 137

tery and fuel cell technology, efficient refrigeration, and computers that consume one-twentieth the energy of conventional laptops.

\section{Identifying Organizational Gaps}

Based on our assessment of business model themes, best practices, and trends, we have developed seven "diagnostic" questions for assessing gaps in organizational capacity to scale.

1. Can the organization develop and maintain a core competence in localizing technology—either through product design or in customization of more complex products and systems integration?

2. Is the organization able to leverage market intelligence to refine segmentation strategies, specify appropriate product line extensions, and define technology roadmaps? Market intelligence is especially important for "distribution only" ventures like Solar Sister in Africa and Onergy in India.

3. Can the organization create distribution channels with positive unit economics and agent incentives?

4. Can the organization provide customer and/or supplier finance? The critical barrier here is the inability of the poor to afford beneficial products with a high up front cost. Software-enabled electronics which facilitate mobile transactions and tie micro-payments to the cash flow constraints of the poor are a potential substitute for customer finance (e.g., Simpa Networks).

5. Has the organization developed a path for becoming embedded in geographic and sector ecosystems through alliances that leverage specialized value chain strengths, mitigate barriers to firm survival, and enhance the organization's position as a trusted brand?

6. Does the organization have a capital efficient scaling strategy that rationalizes tradeoffs between narrow vs. broad geographic reach (e.g., "depth" scaling and the pursuit of holistic solutions to poverty alleviation through multiproduct or services channels vs. "breadth" scaling for a narrowly focused technology solution)? 
7. Does the organization have the right legal structure for facilitating access to a spectrum of capital that is aligned with its mission, market creation challenges, and life cycle stage?

\section{CONCLUSIONS}

As emergent industrial sectors are stimulated and new markets evolve, they typically undergo a process of rationalization. This process is underway in the off-grid energy market. Through specialization, industry standards, market segmentation, and nascent trade associations that are beginning to act as focal points for cooperation and competition, the pace of innovation is quickening. Specialization within the off-grid cluster will accelerate innovation to address what technology historian Thomas Hughes (1983) describes as reverse salients, or the "choke points" in innovation cycles where focused talent and capital investment, as well as efforts to remove policy barriers, can unleash future waves of innovation and contribute to greater investor returns. These dynamics are catalyzing both technological and business model innovation in the BoP energy market.

When we began our work more than a decade ago, business models that enable the poor to afford solar did not exist. Over the course of the ensuing decade, the average poor family could expect to spend $\$ 1,800$ on energy. Today, a significantly brighter 40 watt SHS solution would cost just $\$ 300$, and provide not only superior light but cell-phone charging as well, and power for fans, television, and a computer. Evidence from a decade of work at Santa Clara University suggests that combinatory technology and business model innovation is set to drive expansion and deepen penetration in the off-grid energy market.

\section{REFERENCES}

Bardouille, P. 2012. From gap to opportunity: Business models for scaling

up energy access. IFC/International Finance Corporation.

Bossidy, L., \& Charan, R. 2002. Execution-The discipline of getting things done. New York: Crown Business.

Desa, G., \& Koch, J. L. 2013. Scaling social enterprise: A longitudinal study of social venture growth in rural India. Santa Clara University: Center for Science, Technology, and Society.

Hammond, A., Kramer, W. J., Tran, J., Katz, R., \& Walker, C. 2007. The next 4 billion: Market size and business strategy at the base of the pyramid. World Resources Institute/IFC. 
Innovation Dynamics, Best Practices, and Trends in the Off-Grid Clean Energy Market 139

Hughes, T. P. 1983. Networks of power-Electrification in western society, 1880-1930. Baltimore and London: Johns Hopkins University.

Koh, H., Karamchandani, A., \& Katz, R. 2012. From blueprint to scale: The case for philanthropy in impact investing. Monitor Group in collaboration with Acumen Fund.

Kohler, J., Kreiner, T., \& Sawhney, J. 2011. Coordinating impact capital: A new approach to investing in small and growing businesses. Santa Clara University.

Wimmer, N. 2012. Green energy for a billion poor. Haftungbeschrankt: MCRE Verlag UG. 